\title{
CAPTURING LOST RESEARCH
}

\author{
Rebecca Lawrence, PhD \\ Director, New Product Development
}

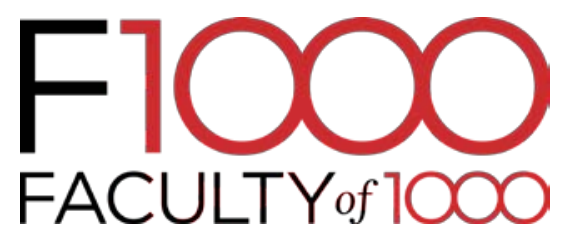


$>$ From the founders of BioMed Central and Current Opinions journals

$>$ Post-publication peer review

$>$ Faculty of 10,000 experts

$>$ Faculty identify and evaluate the most important articles in biology and medicine

$>1,500$ new evaluations per month; $>100,000$ total so far

$>$ Evaluated PubMed

$>$ F1000 includes: Evaluations, Reports, Posters, Naturally Selected

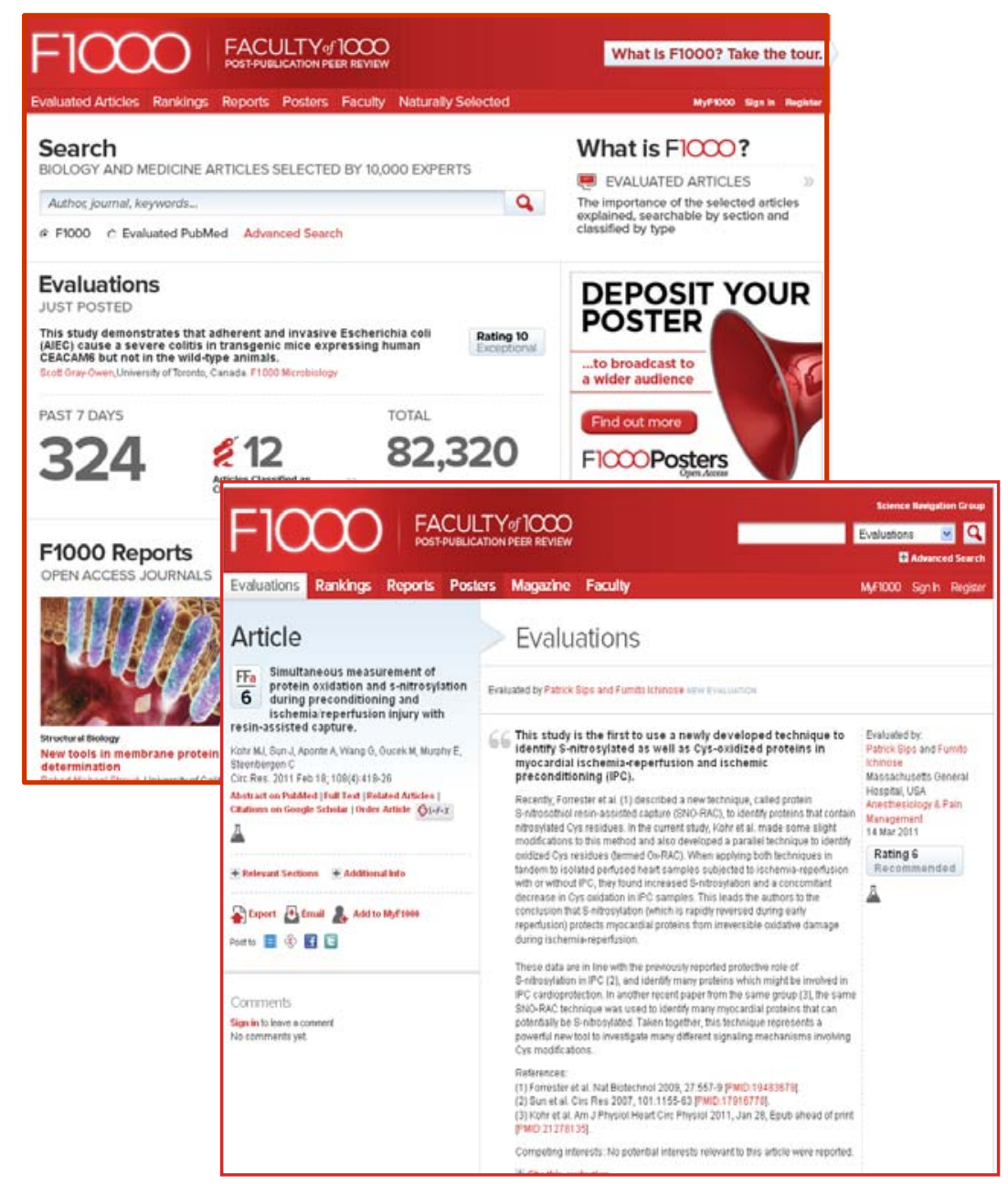


$>$ A unique open access repository for posters across biology \& medicine

$>$ Includes posters from several hundred conferences since June 2010

$>$ Covers leading meetings

$>$ Faculty highlight top posters

$>$ Top performing posters receive $400-1,000+$ views in a month

$>$ Support from presenters, societies and journals alike

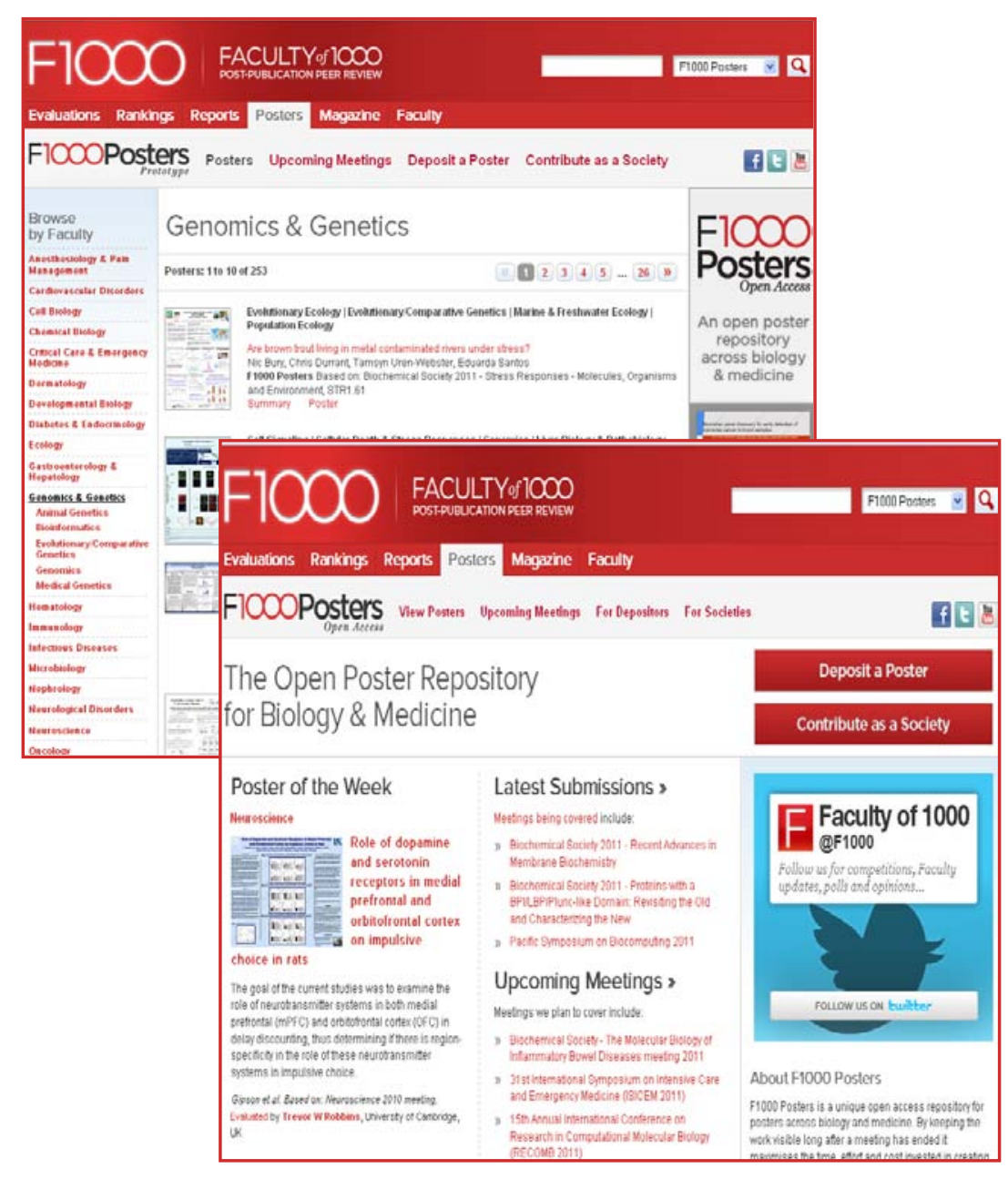




\section{CAPTURING 'LOST' RESEARCH}

$>$ Much research is never published

$>$ Even if presented at a meeting, often never published:

- $76 \%$ posters in F1000 Posters not published before 1 year

- Almost half work presented at ASCB never published (according to their past-president, Bruce Alberts)

$>$ And of course much research never even makes a meeting

$>$ Valuable information that needs capturing:

- Avoid needless repetition

o So that effort is not wasted

o So that others can benefit from work already done 
F1000 is expanding its publishing program into data publishing:

- Separate citable articles focussing on raw datasets

- Submit data via F1000 but is hosted in existing data repositories

- F1000 provides the publication mechanism - DOls, version control, core metadata etc

- Data visible immediately - no delay

- Post-publication peer review 


\section{DATABASES AND STANDARDS}

- Encourage authors to use existing resources and standards

- If none yet exist, help to prompt the creation of new standards

- Need ways to suggest to authors:

- Which databases exist that may be relevant to their topic

- Which of these adhere to agreed standards 
Objectives from this workshop for us:

- Understand what initiatives are already ongoing towards these goals

- Understand how we can usefully support these initiatives

- Contribute where possible, e.g. our Faculty, contacts, internal developments

- Provide input on the information we would find useful to pass onto our authors

- Understand what is required at our end to feed into what is being developed centrally

Rebecca.lawrence@f1000.com 